\title{
Olefin Hydrogenation with Single-Site Gold
}

\author{
J. Szlachetko ${ }^{a, b}$, C. LothschÜtz ${ }^{c}$ AND J. SÁ ${ }^{d, *}$ \\ ${ }^{a}$ Paul Scherrer Institute (PSI), 5232 Villigen-PSI, Switzerland \\ ${ }^{b}$ Institute of Physics, Jan Kochanowski University, 25-406 Kielce, Poland \\ ${ }^{c}$ Syngenta Crop Protection, Münchwilen AG, Breitenloh-5, CH-4333 Muenchwilen, Switzerland \\ ${ }^{d}$ Laboratoire de Spectroscopie Ultrarapide, Ecole Polytechnique Fédérale de Lausanne, 1015 Lausanne, Switzerland
}

\begin{abstract}
Butene hydrogenation activity is intimately connected with the occupied and unoccupied electronic states of gold active site. We prepare well-defined $\mathrm{Au}(\mathrm{III})$ sites in IRMOF-3 structure, and tuned the metal density-of-states by replacing the substituent group of the coordinating group at position 5 . Resonant inelastic X-ray scattering experiments and theoretical calculations revealed an increase in unoccupied $5 d$ states of Au when the substituent group is a donating group, which leads to a dramatic increase in catalytic activity.
\end{abstract}

DOI: $10.12693 /$ APhysPolA.125.940

PACS: 82.80.Dx, 82.20.-w, 82.80.Ej

\section{Introduction}

Until the late eighties, gold was perceived as a non-catalytic metal, however that changed when Haruta et al. discovered that nanosize gold is active in $\mathrm{CO}$ oxidation [1]. Since then a plethora of catalytic processes in which nanogold is active were reported, namely in hydrogenations [2], oxidations [3], hydroaminations [4] and epoxidations [5]. The applications range from environmental remediation [6] to the chemical production [7].

As with any catalytic material, gold activity is intimately related to its electronic structure, which alters when molecules are adsorbed (the initial step of any catalytic process). As reminder, molecules adsorption on a catalyst leads to the formation of new bonding and antibonding states. When the antibonding states are shifted to energy levels above the Fermi level, the molecule bonds to the metal site [8]. Hammer and Nørskov [9] proposed an adsorbate-metal bonding model based on $d$-band theory. The model suggests that adsorption energy depends on the energy position of the $d$-band in respect of the Fermi level. As consequence metals with $d$-band closer to the Fermi level are more prone to adsorb molecules than those with $d$-band further from the Fermi level. Thus, tuning of active site electronic structure is at the forefront of any catalyst development and/or improvement.

Gold modified metal organic frameworks (MOFs) are a novel class of supported gold catalysts. Post-synthetic modification (PSM) of MOFs allows for the design of an active site according to reaction requirements [10]. Iso-reticular MOF3 (IRMOF-3) is a porous MOF decorated with pendant amine $\left(-\mathrm{NH}_{2}\right)$ groups synthesized by Eddaoudi et al. [11]. The amine moieties are available to react because they do not make part of MOF structure [12].

\footnotetext{
*corresponding author; e-mail: jacinto.depaivasa@epfl.ch; jacinto.sa@psi.ch
}

Zhang et al. used a similar PSM strategy to produce a highly active gold-iminophenol functional material able to hydrogenate selectively 1,3-butadiene to butene [13]. They added gold to IRMOF-3 that was previously modified with a salicylaldehyde group. Gold was believed to be present as Au(III). The study did not exploit the possibility to change gold electronic structure by changing salicylaldehyde substituent. Sá et al. [14] demonstrated that gold electronic structure could be finely tuned by replacing the salicylaldehyde substituent groups in benzyl ring (position 5). Most importantly, the changes were quantified by measuring directly the changes in metal $5 d$ density-of-states (DOS) instead of the commonly used methods that infer DOS from coordinating ligand theory. Herein, we report the changes on 1-butene hydrogenation induced by the changes in Au $5 d$ DOS. We performed resonant inelastic X-ray scattering (RIXS) and density functional theory (DFT) calculations to determine $5 d$ DOS, and correlate its influence in the catalytic outcome. It was found that increased in $5 d$ DOS leads to higher catalytic performance.

\section{Experimental}

The samples were prepared according to the procedure described elsewhere [14]. We prepare three Au-IRMOF coordinated with salicylaldehyde group substituted in position 5 by $-\mathrm{NO}_{2}\left(\mathrm{Au}-\mathrm{IRMOF}-\mathrm{NO}_{2}\right),-\mathrm{OCH}_{3}(\mathrm{Au}-$ -IRMOF-OCH $\left.{ }_{3}\right)$, and $-\mathrm{H}(\mathrm{Au}-\mathrm{IRMOF}-\mathrm{H})$. Hydrogenation of 1-butene was carried out in a plug flow reactor at several temperatures $\left(75,100\right.$, and $\left.130^{\circ} \mathrm{C}\right)$ for a total of $3 \mathrm{~h}$. The inlet gas composition was 1-butene/ $\mathrm{H}_{2}(1 \% / 2 \%)$ in Ar, total flow $30 \mathrm{~mL} / \mathrm{min}$. The outlet gas composition as analysed by quadrupole mass spectroscopy, and the molar concentrations were calculated using sensitivity and fragmentation factors calibrated beforehand.

The RIXS maps were measured at the SuperXAS beamline of the Swiss Light Source at the Paul Scherrer Institute, Switzerland. X-ray detection was performed 
with a wavelength-dispersive spectrometer. To avoid any scanning components during the acquisition, the spectrometer was operated in the von Hamos geometry [15]. On the sample the photon flux was $(7-8) \times 10^{11}$ photons $/ \mathrm{s}$ with an energy resolution of $\Delta E / E \approx 1.4 \times 10^{-4}$ and a spot size of $100 \times 100 \mu \mathrm{m}^{2}$. For calibration a $4 \mu \mathrm{m}$ thick $\mathrm{Au}$ foil was used. The samples were measured as wet powder (in toluene) compressed between kapton tape (100 $\mu \mathrm{m}$ thick) at $-90^{\circ} \mathrm{C}$ to prevent beam damage, which was evaluated throughout the measurements.

The orbitals energetic position and HOMO-LUMO gap were calculated with the Gaussian09 program package [16]. The geometry optimizations of the gold complexes were performed at the density functional theory (DFT) level, employing the Becke three-parameter B3LYP functional [17] together with a cc-pVDZ basis [18] on all atoms. For gold a relativistic effective core-potential (RECP) was employed [19], where 54 electrons were taken into the core. The corresponding valence basis suitable for this pseudo-potential also had cc-pVDZ quality and was optimized by Peterson and Puzzarini [20]. The relativistic effects, especially $s$-orbital contraction and $d$-orbital expansion, are accurately accounted for by the RECP; DFT/RECP has proven to be very successful for calculations of organometallic compounds [21].

\section{Results and discussion}

$\mathrm{Au}$-IRMOF catalysts were tested on the hydrogenation of 1-butene to butane. When active, the only reaction product detected was butane, as expected if hydrogenation is the single process taking place. The overall activity decreased with the increase of reaction temperature (Fig. 1 and Table I). The result suggests that the amount of 1-butene adsorbed is a key factor of the process since 1-butene adsorption decreases with the rise of temperature. Thus, one can confidently state that 1-butene has a low heat of adsorption on the present gold sites.

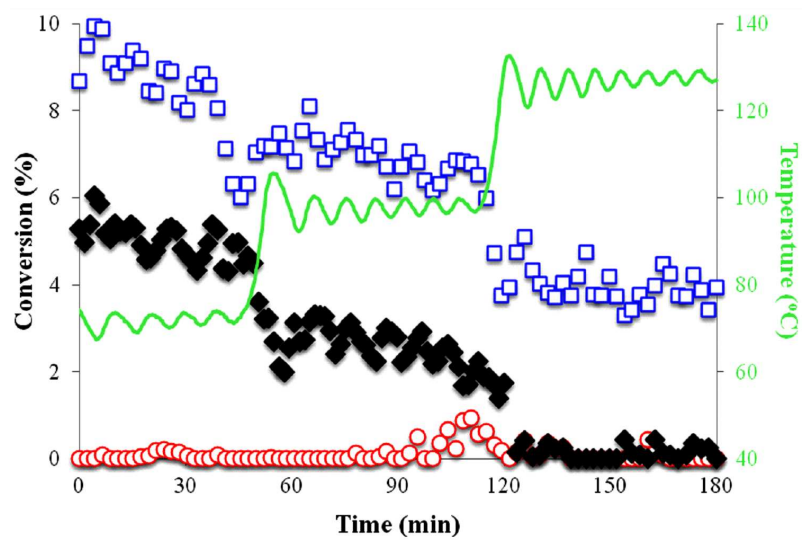

Fig. 1. Conversion values for 1-butene hydrogenation over Au-IRMOF as a function of reaction temperature. $\square \mathrm{Au}$-IRMOF-OCH $\mathrm{OCH}_{3}$ Au-IRMOF-H, 。 Au-IRMOF$-\mathrm{NO}_{2},-$ temperature in Celsius.

\section{TABLE I}

Average conversion of 1-butene over Au-IRMOF as a function of reaction temperature.

\begin{tabular}{c|c|c|c}
\hline \hline & $\begin{array}{c}\text { Au-IRMOF-NO } \\
\text { [ }\end{array}$ & $\begin{array}{c}\text { Au-IRMOF-H } \\
{[\%]}\end{array}$ & $\begin{array}{c}\text { Au-IRMOF-OCH } \\
\text { [\%] }\end{array}$ \\
\hline $75^{\circ} \mathrm{C}$ & not detected & $4.5 \pm 1.3$ & $8.2 \pm 1.4$ \\
$100{ }^{\circ} \mathrm{C}$ & not detected & $2.3 \pm 1.0$ & $6.6 \pm 1.3$ \\
$130^{\circ} \mathrm{C}$ & not detected & not detected & $4.0 \pm 1.0$
\end{tabular}

The Au-IRMOF-H (Zhang et al. system [13]) is active at 75 and $100{ }^{\circ} \mathrm{C}$ but not at $130^{\circ} \mathrm{C}$, which is consistent with Zhang's findings. They reported close to $100 \%$ selectivity to 1-butene in 1,3-butadiene hydrogenation at $130^{\circ} \mathrm{C}$, i.e., olefin hydrogenation does not take place. Substitution of substituent group in salycilaldehyde position 5 by a deactivating group (Au-IRMOF$-\mathrm{NO}_{2}$ ) led to complete suppression of 1-butene hydrogenation. This contrasts, with an enhancement of activity when the same position was substituted with an activating group (Au-IRMOF-OCH ${ }_{3}$ ) (see Table I).

In an attempt to rationalize the finding, we performed RIXS measurements and DFT calculations. It should be mentioned that the choice of position 5 was deliberate since it avoids or drastically decreases potential geometric factors since spatial availability around the active site remain unaltered. RIXS spectroscopy at $L_{3}$ edge is an ideal tool to probe $5 d$ unoccupied states of Au. Thanks to the strong dipolar resonance $\left(2 p_{3 / 2} \rightarrow 5 d\right)$, small changes in Au empty $d$-states population can be resolved. Following the electron excitation, a core-to-core $\mathrm{X}$-ray emission is detected corresponding to the $L_{\alpha_{1}}\left(3 d_{5 / 2} \rightarrow 2 p_{3 / 2}\right.$ decay) X-ray fluorescence. Because of low electron coupling between excited $5 d$ and decaying $3 d$ electrons, the measured data can be directly evaluated and compared with theoretical calculations.

Figure 2 shows the RIXS plane differences between active ( $\mathrm{H}$ top, $\mathrm{OCH}_{3}$ bottom) and non-active $\left(\mathrm{NO}_{2}\right)$ sites. Similar to previous studies [14], the resonance corresponding to $d$-excitation is detected at incidence beam energy of around $11919 \mathrm{eV}$. The $\Delta$-RIXS plane for $\mathrm{H}$ and $\mathrm{NO}_{2}$ samples reveals an increase in Au $5 d$ DOS of about $7 \%$ in case of Au-IRMOF-H. Comparison between $\mathrm{Au}-\mathrm{IRMOF}-\mathrm{OCH}_{3}$ with non-active $\mathrm{Au}-\mathrm{IRMOF}-\mathrm{NO}_{2}$, reveals that a significant change $d$-band population is detected. A $19 \%$ increase in unoccupied Au d-band was detected when the withdrawing substituent group $\left(-\mathrm{NO}_{2},\right)$ is replaced by a donating group $\left(-\mathrm{OCH}_{3}\right)$. Both $\Delta$-RIXS planes could be reproduced with theoretical simulations (Fig. 2, right). Thus the observed changes are in fact related to changes in Au electronic structure due to the substituent group.

Effect of the electronic rearrangement induced by salicylaldehyde group substituted in position 5 and its impact on $\mathrm{Au} 5 d$ DOS was detected and confirmed with theoretical simulations, confirming PSM as a viable synthetic strategy to tune DOS, and consequently the catalytic performance. The signal differences seen at higher 

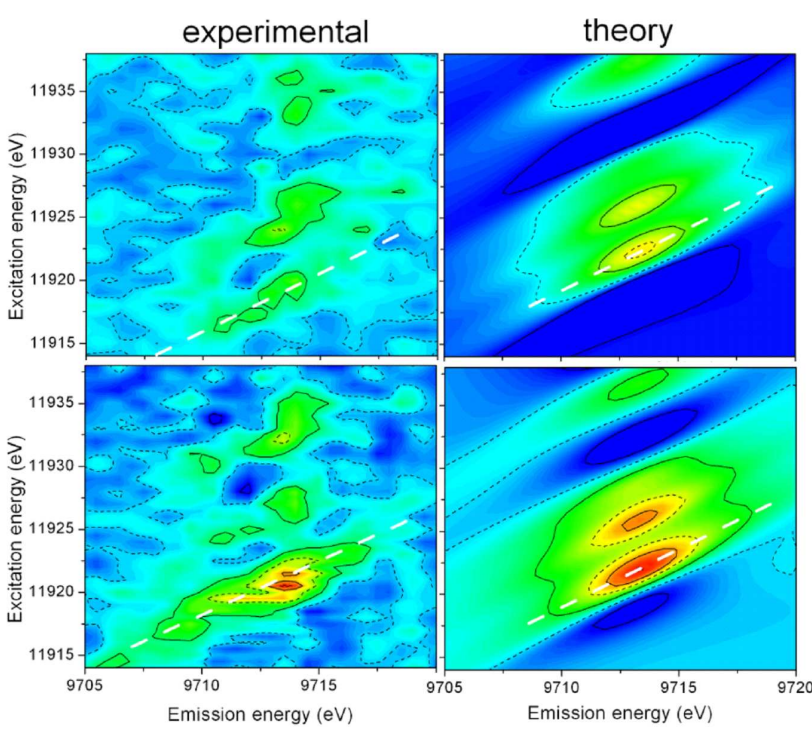

Fig. 2. RIXS map differences, experimental (left) and theoretical (right). (top) $\Delta$-RIXS (Au-IRMOF-H - $\mathrm{Au}$-IRMOF-NO ${ }_{2}$ ); (bottom) $\Delta$-RIXS (Au-IRMOF$\left.-\mathrm{OCH}_{3}-\mathrm{Au}-\mathrm{IRMOF}-\mathrm{NO}_{2}\right)$.

excitation energies (11925 eV and $11935 \mathrm{eV}$ ) are due to the changes in multi-electron scattering cross-sections probabilities. This signal is also well reproduced by theoretical simulations.

RIXS maps analysis revealed that the Au $5 d$ DOS increases when an activating group is in position, and vice versa. DFT calculations corroborated this finding.

\section{TABLE II}

LUMO-HOMO gap calculated with DFT.

\begin{tabular}{c|c}
\hline \hline & $\Delta E[$ LUMO-HOMO] [eV] \\
\hline $\mathrm{Au}$-IRMOF-NO & \\
$\mathrm{Au}-\mathrm{IRMOF-H}$ & 3.12 \\
$\mathrm{Au}-\mathrm{IRMOF-OCH}$ & 2.95 \\
& 2.54
\end{tabular}

DFT calculations revealed a decrease in the gap between lowest unoccupied molecular orbital (LUMO) and highest occupied molecular orbital (HOMO) when an activating group is in position 5 (Table II). Thus, these structures are more prone to adsorb 1-butene, and undergo reaction according to Nørskov et al. [9] proposed adsorbate-metal bonding model based on $d$-band theory.

Concerning the reaction mechanism, adsorption of 1-butene can only occur if one of the chloro groups coordinated to the $\mathrm{Au}$ is displaced. Bond length calculations were performed to evaluate if there is a preferential site when the double adsorbs.

Calculated bond lengths between $\mathrm{Au}$ and atoms in the first coordination shell.<smiles></smiles><smiles></smiles><smiles></smiles>

Ethen1

Ethen2

\begin{tabular}{|c|c|c|c|c|c|c|}
\hline Compound & $\begin{array}{c}\mathrm{Au}-\mathrm{Cl} 1 \\
{[\mathrm{pm}]}\end{array}$ & $\begin{array}{c}\mathrm{Au}-\mathrm{Cl} 2 \\
{[\mathrm{pm}]}\end{array}$ & $\begin{array}{l}\mathrm{Au}-\mathrm{O} \\
{[\mathrm{pm}]}\end{array}$ & $\begin{array}{l}\mathrm{Au}-\mathrm{N} \\
{[\mathrm{pm}]}\end{array}$ & $\begin{array}{l}\text { Au-Ethen } \\
\left(\mathrm{C}_{1}\right)[\mathrm{pm}]\end{array}$ & $\begin{array}{l}\text { Au-Ethen } \\
\left(\mathrm{C}_{2}\right)[\mathrm{pm}]\end{array}$ \\
\hline $\mathrm{Au}-\mathrm{IRMOF}-\mathrm{NO}_{2}$ & 230.09 & 229.74 & 209.11 & 204.19 & - & - \\
\hline $\mathrm{Au}$-IRMOF-NO ${ }_{2}$-Ethen1 & 231.75 & - & 208.70 & 200.83 & 228.52 & 228.51 \\
\hline $\mathrm{Au}$-IRMOF-NO ${ }_{2}$-Ethen2 & - & 230.49 & 207.06 & 202.24 & 232.30 & 232.30 \\
\hline Au-IRMOF-H & 230.48 & 230.30 & 208.54 & 203.35 & - & - \\
\hline Au-IRMOF-H-Ethen1 & 232.08 & - & 208.35 & 200.19 & 229.13 & 228.20 \\
\hline Au-IRMOF-H-Ethen2 & - & 230.94 & 206.39 & 201.58 & 232.04 & 232.05 \\
\hline $\mathrm{Au}-\mathrm{IRMOF}-\mathrm{OCH}_{3}$ & 230.58 & 230.43 & 208.33 & 203.19 & - & - \\
\hline $\mathrm{Au}$-IRMOF-OCH${ }_{3}$-Ethen1 & 232.08 & - & 208.35 & 200.19 & 229.13 & 228.20 \\
\hline $\mathrm{Au}$-IRMOF-OCH${ }_{3}$-Ethen2 & - & 230.94 & 206.39 & 201.58 & 232.04 & 232.05 \\
\hline
\end{tabular}

Table III summarizes the bond lengths after olefin adsorption. In order to decrease the computational time, we performed the calculations with ethene instead of butene, however back of the envelope calculations revealed comparable results, which certifies consistence and transfer- ability of the observations. Bond lengths are consistently shorter when the double bond replaces $\mathrm{Cl}_{2}$ however the differences are small to suggest that there is a preferential adsorption site. Hydrogen activation remains unsolved but hydrogen activation on small gold metal nanoparti- 
cles cannot be discarded. It should be mentioned that we did not detect small metal particles but they can be present in levels below our detection limit.

\section{Conclusion}

In conclusion, we demonstrate that $\mathrm{Au} 5 d$ DOS can be tuned by replacing the substituent group of the coordinating group. The addition of withdrawing group led to a significant increase of the HOMO-LUMO gap, which consequently decreased the catalytic activity. Inversely, the addition of a donating group shrinks the HOMOLUMO gap, which promoted the reaction. Thus, PSM of MOFs offers the possibility to finely tune the metal electronic states, and consequently catalytic performance. The combination of RIXS and theoretical calculations is extremely powerful approach, enabling access to a detailed picture of factors controlling catalytic outcome, namely catalyst electronic states.

\section{Acknowledgments}

The authors would like to acknowledge Paul Scherrer Institute for the access to the SuperXAS beamline, and the help from its team. We would like to acknowledge Marco Servalli from Prof. van Bokhoven's group for the samples. We would like to acknowledge Dr. Smolentsev for XAS data that were used as input for RIXS map calculations. We acknowledge Evgeny Kleymenov, Maarten Nachtegaal, Marco Ranocchiari, and Olga V. Safonova for helping with the project.

\section{References}

[1] M. Haruta, T. Kobayachi, H. Sano, N. Yamada, Chem. Lett. 2, 405 (1987); M. Haruta, Nature 437, 1098 (2005).

[2] For example: A. Corma, C. González-Arellano, M. Iglesias, F. Sánchez, Appl. Catal. A 356, 99 (2009); D.A. Cadenhead, N.G. Masse, J. Phys. Chem. 70, 3558 (1966); J.E. Bailie, G.J. Hutchings, Chem. Commun., 2151 (1999); P. Claus, H. Hofmeister, C. Mohr, Gold Bull. 37, 181 (2004).

[3] For example: S. Biella, L. Prati, M. Rossi, J. Catal. 206, 242 (2002); P. Landon, P.J. Collier, A.J. Papworth, C.J. Kiely, G.J. Hutchings, Chem. Commun., 2058 (2002); S. Carrettin, P. McMorn, P. Johnston, K. Griffin, G.J. Hutchings, Chem. Commun., 696 (2002); M.D. Hughes, Y.J. Xu, P. Jenkins, P. McMorn, P. Landon, D.I. Enache, A.F. Carley, G.A. Attard, G.J. Hutchings, F. King, E.H. Stit, P. Johnston, K. Griffin, C.J. Kiely, Nature 437, 1132 (2005); J.-D. Grunwaldt, C. Kiener, C. Wögerbauer, A. Baiker, J. Catal. 181, 223 (1999); P. Haider, A. Baiker, J. Catal. 248, 175 (2007).

[4] A. Corma, P. Concepción, I. Domínguez, V. Fornés, M.J. Sabater, J. Catal. 251, 39 (2007).

[5] For example: T. Hayashi, K. Tanaka, M. Haruta, J. Catal. 178, 566 (1998); A.K. Sinha, S. Seelan, S. Tsubota, M. Haruta, Top. Catal. 29, 95 (2004); A. Corma, I. Domínguez, A. Doménech, V. Fornés, C.J. Gómez-García, T. Ródenas, M.J. Sabater, J. Catal. 265, 238 (2009).
[6] M. Magureanu, N.B. Mandache, J. Hu, R. Richards, M. Florea, V.I. Parvulescu, Appl. Catal. B 76, 275 (2007).

[7] C.W. Corti, R.J. Holliday, D.T. Thompson, Appl. Catal. A 291, 253 (2005).

[8] B. Hammer, J.K. Nørskov, Adv. Catal. 45, 71 (2000).

[9] B. Hammer, J.K. Nørskov, Surf. Sci. 343, 211 (1995).

[10] S.M. Cohen, Chem. Sci. 1, 32 (2010).

[11] M. Eddaoudi, J. Kim, N. Rosi, D. Vodak, J. Wachter, M. O'Keeffe, O.M. Yaghi, Science 295, 469 (2002).

[12] Z. Wang, S.M. Cohen, J. Am. Chem. Soc. 129, 12368 (2007); J.S. Seo, D. Whang, H. Lee, S.I. Jun, J. Oh, Y.J. Jeon, K. Kim, Nature 404, 982 (2000).

[13] X. Zhang, F.X. Llabres i Xamena, A. Corma, J. Catal. 265, 155 (2009).

[14] J. Sá, J. Szlachetko, E. Kleymenov, C. Lothschütz, M. Nachtegaal, M. Ranocchiari, O.V. Safonova, M. Servalli, G. Smolentsev, J.A. van Bokhoven, $R S C$ Adv. 3, 12043 (2013).

[15] J. Szlachetko, M. Nachtegaal, E. de Boni, O. Safonova, J. Sá, G. Smolentsev, M. Szlachetko, J.A. van Bokhoven, J.-C. Dousse, J. Hoszowska, Y. Kayser, P. Jagodzinski, A. Bergamaschi, B. Schmid, C. David, A. Lücke, Rev. Sci. Instrum. 83, 103105 (2012).

[16] Gaussian 09, Revision A.1, M.J. Frisch, G.W. Trucks, H.B. Schlegel, G.E. Scuseria, M.A. Robb, J.R. Cheeseman, G. Scalmani, V. Barone, B. Mennucci, G.A. Petersson, H. Nakatsuji, M. Caricato, X. Li, H.P. Hratchian, A.F. Izmaylov, J. Bloino, G. Zheng, J.L. Sonnenberg, M. Hada, M. Ehara, K. Toyota, R. Fukuda, J. Hasegawa, M. Ishida, T. Nakajima, Y. Honda, O. Kitao, H. Nakai, T. Vreven, J.A. Montgomery, Jr., J.E. Peralta, F. Ogliaro, M. Bearpark, J.J. Heyd, E. Brothers, K.N. Kudin, V.N. Staroverov, R. Kobayashi, J. Normand, K. Raghavachari, A. Rendell, J.C. Burant, S.S. Iyengar, J. Tomasi, M. Cossi, N. Rega, J.M. Millam, M. Klene, J.E. Knox, J.B. Cross, V. Bakken, C. Adamo, J. Jaramillo, R. Gomperts, R.E. Stratmann, O. Yazyev, A.J. Austin, R. Cammi, C. Pomelli, J.W. Ochterski, R.L. Martin, K. Morokuma, V.G. Zakrzewski, G.A. Voth, P. Salvador, J.J. Dannenberg, S. Dapprich, A.D. Daniels, Ö. Farkas, J.B. Foresman, J.V. Ortiz, J. Cioslowski, D.J. Fox, Gaussian, Inc., Wallingford CT, 2009.

[17] A.D. Becke, J. Chem. Phys. 98, 5648 (1993); C. Lee, W. Yang, R.G. Parr, Phys. Rev. B 37, 785 (1988).

[18] T.H. Dunning, J. Chem. Phys. 90, 1007 (1989).

[19] D. Figgen, G. Rauhut, M. Dolg, H. Stoll, Chem. Phys. 311, 227 (2005).

[20] K.A. Peterson, C. Puzzarini, Theor. Chem. Acc. 114, 283 (2005).

[21] S. Niu, M.B. Hall, Chem. Rev. 100, 353 (2000). 